\title{
A comparison of ANN and HSPF models for runoff simulation in Gharehsoo River watershed, Iran
}

\author{
Kazem Javan ${ }^{1} \cdot$ Mohammad Reza Fallah Haghgoo Lialestani ${ }^{2} \cdot$ Majid Nejadhossein $^{3}$
}

Received: 20 October 2015/Accepted: 31 October 2015/Published online: 19 November 2015

(C) Springer International Publishing Switzerland 2015

\begin{abstract}
In this study, the capability of two different types of model including Hydrological Simulation Program-Fortran (HSPF) as a process-based model and Artificial Neural Networks (ANNs) as a data-driven model in simulating runoff were evaluated. The area considered is the Gharehsoo River watershed in northwest Iran. HSPF is a semi distributed Deterministic, continuous and physically-Based model that can simulate the hydrologic, associated water quality and quantity, processes on pervious and impervious land surfaces and streams. ANN is probably the most successful machine learning technique with flexible mathematical structure which is capable of identifying complex non-linear relationships between input and output data without attempting to reach understanding as to the nature of the phenomena. Statistical approach depending on cross-, auto- and partial-autocorrelation of the observed data is used as a good alternative to the trial and error method in identifying model inputs. The performance of ANN and HSPF models in calibration and testing stages are compared with the observed runoff values to identify the best fit forecasting model based upon a number of selected performance criteria. Results of runoff simulation indicate that simulated runoff by ANN were generally closer to observed values than those predicted by HSPF.
\end{abstract}

Kazem Javan

kazem.javan.tmu@gmail.com

1 Department of Civil and Environmental Engineering, Tarbiat Modares University Iran, Tehran, Iran

2 Department of Civil and Environmental Engineering, Ferdowsi University, Mashhad, Iran

3 Department of Civil and Environmental Engineering, Islamic Azad University Shoshtar Branch, Shushtar, Iran
Keywords HSPF model - Artificial neural network (ANN) - Runoff simulation · Gharehsoo River watershed
Abbreviations
ANN Artificial neural network
HSPF Hydrological simulation program-fortran
FFNN Feed forward neural network

\section{Introduction}

Streamflow is one of the most important processes in the hydrological cycle and its prediction, is vital for water resources management and planning (Kahya and Dracup 1993). Computer simulation models of watershed hydrology and artificial intelligent techniques are widely used for runoff simulation and forecasting. The use of watershed models is increasing in need to growing demands for improved runoff quantity.

Over the last decades, artificial intelligent techniques have been introduced and widely applied in hydrological studies as powerful alternative modelling tools, such as artificial neural networks (ANN) (Dawson and Wilby 2001; Bray and Han 2004; Nayak et al. 2007; Goel 2009; Banaei et al. 2012; Javan et al. 2015), fuzzy inference system (FIS) (Zadeh 1965; See and Openshaw 2000; Xiong et al. 2001; Nayak et al. 2007). In addition, Shamseldin (1997), Tokar and Johnson (1999), Kumar et al. (2005), Filho and dos Santos (2006), Chua et al. (2008) and Mutlu et al. (2008) compared ANNs with different input variables for runoff simulation. The comparisons show that the ANN models with rainfall and discharge as input variables give better results than the models with rainfall inputs. When the 
model utilizes of rainfall as the input variables, the simulated hydrographs do not match the measured hydrographs so good (see Halff et al. 1993; Kumar et al. 2005; Filho and dos Santos 2006; Mutlu et al. 2008). Although good fits between the simulated and measured hydrographs have been reported in other studies where additional variables such as temperature (Zhang and Govindaraju 2000), evaporation (Kingston et al. 2005), soil moisture (Abrahart and See 2007) have been included as inputs to the ANN model.

Hydrological simulation program-fortran (HSPF) is a semi-distributed, conceptual model that combines spatially distributed physical attributes into hydrologic response units. In this model surface runoff is simulated primarily as an infiltration-excess process. HSPF has been used for simulation of various hydrologic conditions (Srinivasan et al. 1998; Zarriello and Ries 2000), non-point source pollutants, including contaminated sediment (Fontaine and Jacomino 1997), and land use management and flood control scenarios (Donigianet al. 1997). Abdullah et al. (2009) have used of HSPF model for runoff simulation of a watershed in Jordan. The results showed that monthly calibration and verifications produced good fit with correlation coefficient equal to 0.928 and 0.923 , respectively. Also, daily simulation results showed lower correlation coefficient 0.785 . Al-Abed and Whiteley (2002) applied HSPF model for runoff simulation in the Grand River watershed; located in Southern Ontario, Canada, with drainage area about $6965 \mathrm{~km}^{2}$. Their study revealed very satisfactory results in the calibration step and the percentage error between the simulated and the observed yearly discharge ranged between 4 and $16 \%$.
Not only ANNs and HSPF have been widely used for runoff simulation, but also many researchers have been performed based on the comparison between mathematical models and ANNs (Tokar and Markus 2000; Morid et al. 2002; Srivastava et al. 2006). In this study ANN and HSPF are evaluated for the simulation of Gharehsoo River stream flow (Iran).

\section{The study area}

This study was directed for the watershed of Ardebil province in North-western Iran, which lies between latitude $37^{\circ}$ to $38^{\circ} \mathrm{N}$ and longitude $47^{\circ}$ to $48^{\circ} \mathrm{E}$ (Fig. 1). The geographical information and the mean observed climate data for the seven main synoptic stations of the province for the baseline years between 1951 and 2007 are depicted in Table 1 . The mean annual precipitation in this watershed (Table 1) is very little in comparison with world average of $800 \mathrm{~mm}$. In recent years, the water shortage in Ardebil city (the capital of the province) that used in excess of water resource for agricultural province and industry consumptions, become a serious problem for this province. Land use is mainly open grass (former pasture and hay fields), mountain, and agriculture, rural and urban residential. The mean annual precipitation in this watershed (stations are presented in Table 1) is very little in comparison with world average of $800 \mathrm{~mm}$. The slope watershed is variable between 0 and $60 \%$ that the lowest slope in central watershed is between 0 and $2 \%$. The pictures satellites are of LAND SAT5 satellite that these have taken in 2006 year (Fig. 2).
Fig. 1 Gharehsoo River watershed and its location in Iran with its topography, drainage network and climate stations

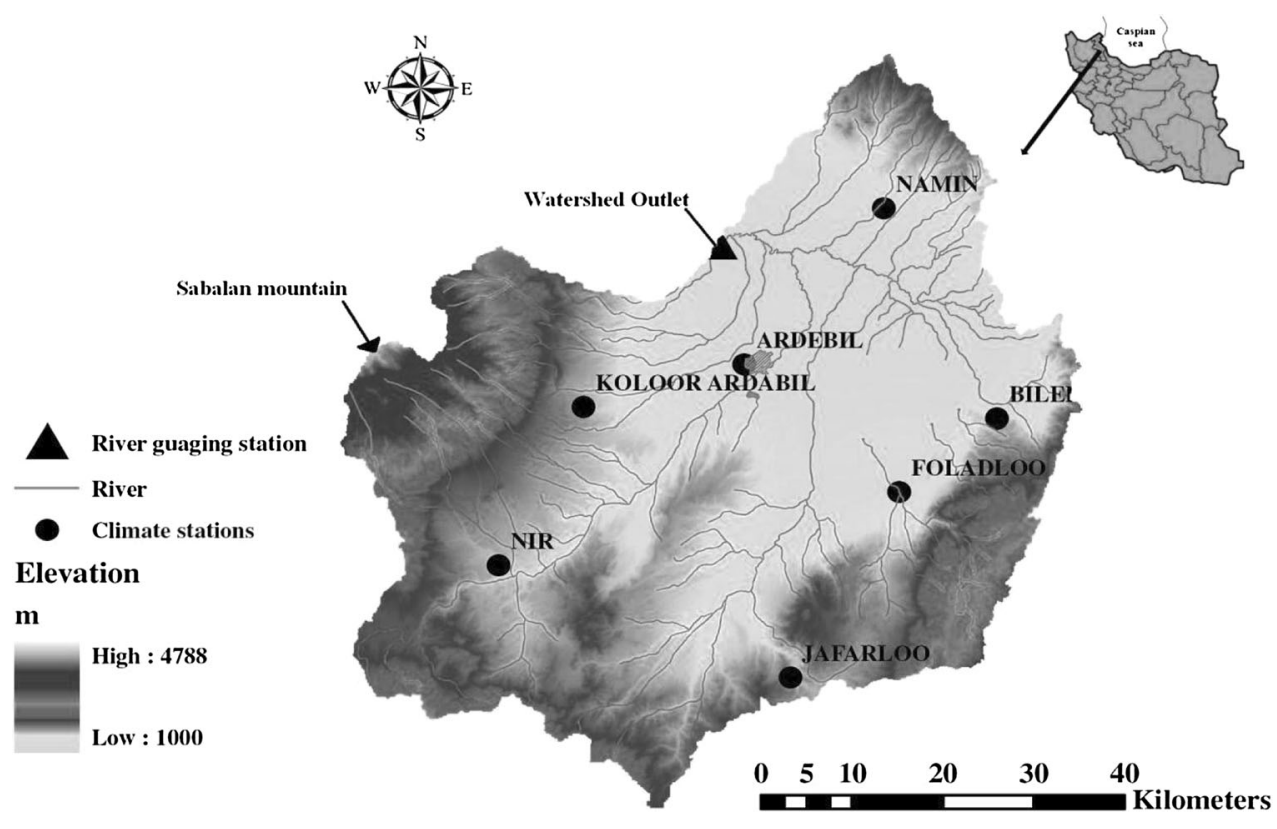


Table 1 The positions and the averages of the precipitation and temperature of seven climate stations

\begin{tabular}{llllllll}
\hline & \multicolumn{2}{l}{ Stations } & & & & \\
\cline { 2 - 7 } & Ardebil & Bile & Foladloo & Jafarloo & Namin & Nir & Koloor Ardebil \\
\hline Latitude $\left({ }^{\circ} \mathrm{E}\right)$ & 38.25 & 38.02 & 38.12 & 37.92 & 38.42 & 38.03 & 38.20 \\
Longitude $\left({ }^{\circ} \mathrm{N}\right)$ & 48.28 & 48.60 & 48.48 & 48.35 & 48.45 & 47.98 & 48.08 \\
Elavation $(\mathrm{m})$ & 1332 & 1680 & 1490 & 1680 & 1500 & 1450 & 1581 \\
Available data (years) & $1951-2007$ & $1975-2007$ & $1994-2007$ & $1969-2007$ & $1960-2007$ & $1960-2007$ & $1975-2007$ \\
Mean precipitation $(\mathrm{mm})$ & 445 & 480 & 334 & 359 & 360 & 376 & 458 \\
Mean temperature $\left({ }^{\circ} \mathrm{C}\right)$ & 10.3 & 8.4 & 6.3 & 7.6 & 8.3 & 7.4 & 8.4 \\
\hline
\end{tabular}

Fig. 2 Land use of Gharehsoo River watershed (LAND SAT5 satellite _ 2006)

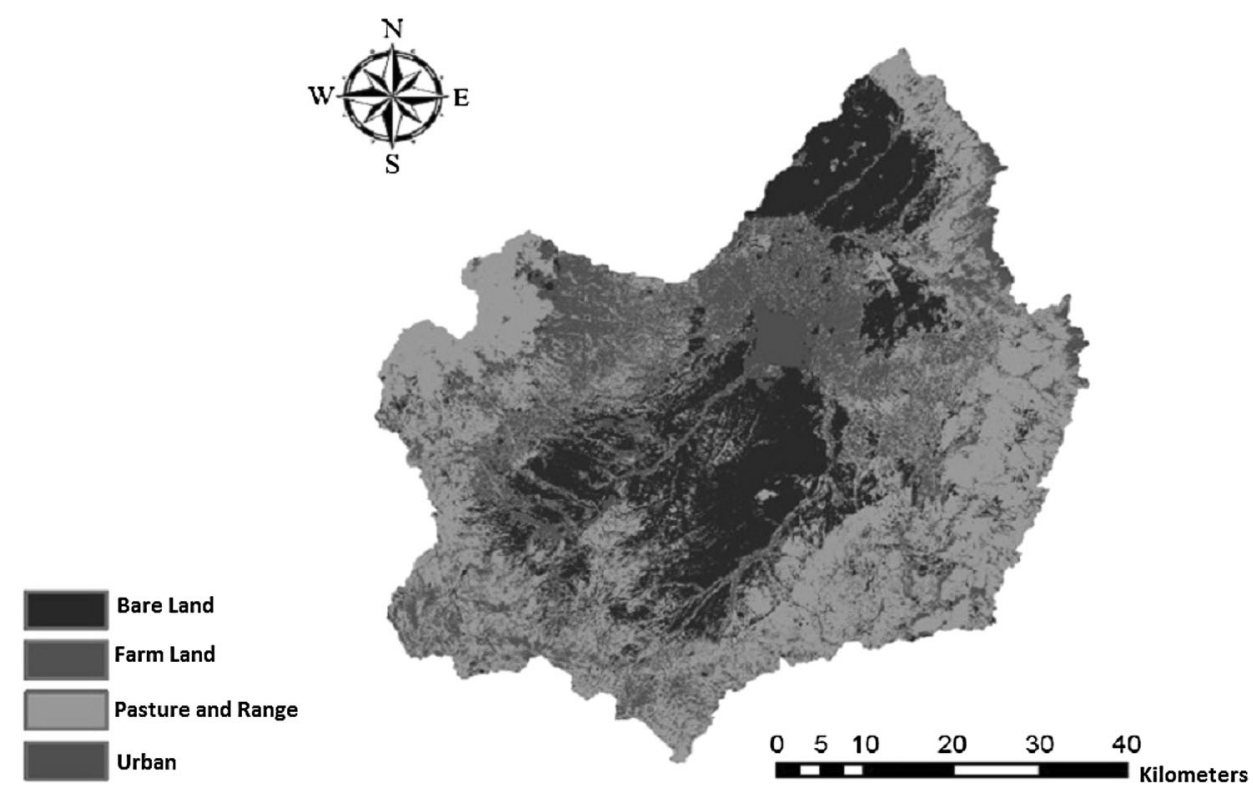

HSPF is a semi distributed deterministic, continuous and physically based model. The PERLND, IMPLND, and RCHRES modules are three main modules of HSPF which help to simulate permeable land segments, impermeable land segments, and free-flow reaches, respectively. Detailed information about these modules can be found in the literatures (Bicknel et al. 1993; Donigian and Crawford 1976; Donigian et al. 1984; Bicknell et al. 2005). Figure 3 exhibits the hydrological cycle processes in HSPF model. HSPF model uses a Storage Routing technique to route water in each reach. Infiltration in permeable land is calculated based on Richard's equation (Bicknell et al. 2005). Actual evapotranspiration (ET) is calculated by Penman or Jensen formulas. Table 2 shows key HSPF parameters. These parameters should be calibrated during the calibration process. LZSN is the lower zone nominal capacity. That is the most important parameter in infiltration capacity which is called in HSPF with the INFILT parameter. AGWRC is defined as the rate of flow today divided by the rate of flow yesterday that is depended on topography, climate, soil properties and land use. UZSN is influenced of 


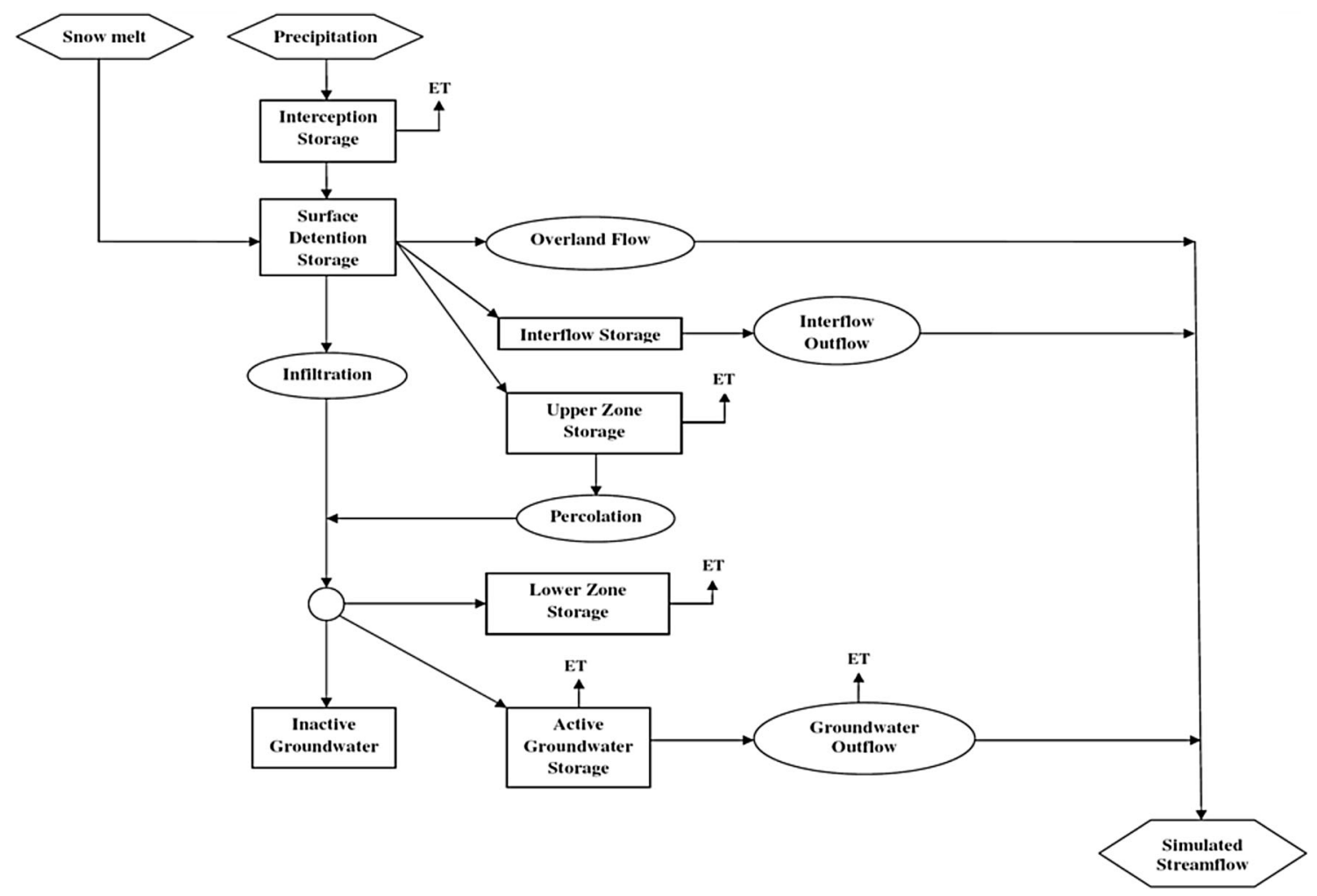

Fig. 3 HSPF conceptual hydrologic model (Mark et al. 2003)

LZSN (Albek et al. 2004). Other parameters that they have not presented in Table 2 are estimated using the BASINS software based on topographic, soil properties and land use data. Then the estimated parameters are introduced to HSPF. The BASINS (Better Assessment Science Integrating Point and Nonpoint Sources) is developed to promote better assessment and integration of point and nonpoint sources in watershed and water quality management. It integrates several key environmental data sets with improved analysis techniques. Several types of environmental programs can benefit from the use and application of such an integrated system in various stages of environmental management planning and decision making (Bicknell et al. 2005). The data from 1998 to 2004 were utilized for HSPF model calibration and the data from 2005 to 2007 were used as validation dataset.

\section{Artificial neural network (ANN)}

The ANN technique has attracted a great deal of attention due to its pattern recognition capabilities. ANNs with one hidden layer are commonly used in hydrologic modeling (Dawson and Wilby 2001; de Vos and Rientjes 2005) since these networks are considered to provide enough complexity to accurately simulate the nonlinear-properties of the hydrologic process. A FFNN consists of at least three layers, input, output and hidden layers. The first step when applies ANN, is based on the selection of network architecture. After selecting the networkarchitecture, the next step is to determine the training algorithm. The most common training for multi-layer feedforward neural networks is the back-propagation algorithm (Hagan and Menhaj 1994; Hagan et al. 1996). The transfer function used in this study is the Sigmoid Function. The sigmoid transfer function allows non-linearity to be introduced in the neural network processing and is broadly used in ANN modeling (Shamseldin 1997).

The input signals presented to the system in input layer are processed in forward through to the hidden layer. The input signal can be a single signal or an array of signals, whereas the output signal is typically single. The summation of weighted input signals is transferred by a nonlinear activation function. The response of network is compared with the actual observation results and the network error is calculated. The error of network is propagated backwards through the system and the weight coefficients updated (Fig. 4).

The most common ANN network is the feed-forward network, which uses the back-propagation algorithm for calibration (Bougadis et al. 2005). The number of neurons contained in the input and output layers, which are determined by the number of input and output variables of a 
Table 2 The parameters of HSPF model in simulation process (EPA 2001)

\begin{tabular}{lllll}
\hline Parameter & Definition & Units & Possible range \\
\cline { 4 - 5 } & & & MIN & MAX \\
\hline INFILT & Index of infiltration capacity & $\mathrm{mm} / \mathrm{h}$ & 0.25 & 12.7 \\
AGWRC & Base groundwater recession & dimensionless & 0.85 & 0.999 \\
LZSN & Lower zone nominal soil moisture storage & $\mathrm{mm}$ & 50.8 & 381 \\
UZSN & Upper zone nominal soil moisture storage & $\mathrm{mm}$ & 1.27 & 50.4 \\
DEEPFR & Fraction of groundwater inflow to deep recharge & dimensionless & 0 & 0.5 \\
INTFW & Interflow inflow parameter & dimensionless & 1 & 10 \\
IRC & Interflow recession parameter & dimensionless & 0.3 & 0.85 \\
BASETP & Fraction of remaining ET from base flow & dimensionless & 0 & 0.2 \\
LZETP & Lower zone ET parameter & dimensionless & 0.1 & 0.9 \\
\hline
\end{tabular}

$Q_{t}=f\left(P_{t-1}, P_{t-2}, P_{t-3}, P_{t-4}, T_{t-1}, T_{t-2}\right)$

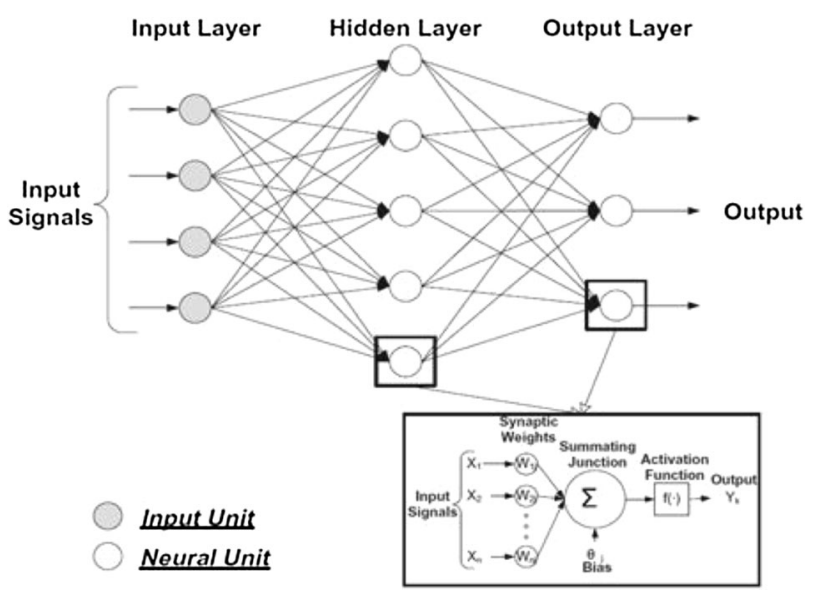

Fig. 4 A three-layered FFNN with a back-propagation calibrating algorithm (Chang et al. 2007)

given system. The size or number of neurons of a hidden layer is an important consideration when solving problems using multilayer feed-forward networks. If there are fewer neurons within a hidden layer, there may not be enough opportunity for the neural network to capture the intricate relationships between indicator parameters and the computed output parameters. Here, we used three-layer FFNN with one hidden layer and the common trial and error method to select the number of hidden nodes. Too many hidden layer neurons not only require a large computational time for accurate calibrating, but may also result in overtraining. A neural network is said to be "overtrained" when the network focuses on the characteristics of individual data points rather than just capturing the general patterns present in the entire calibrating set.

Understanding the temporal relationship between climatic variables and runoff is fundamental to the model development. To predict one lead day runoff $Q_{(\mathrm{t}+1)}$, different variants of input variables are considered. The best MLP architecture is chosen according to MSE criterion. Therefore a total number of six variables were identified as inputs (Eq. 1).
After the appropriate input vector was identified, the network was trained to predict future data based on past and present data. In the present study, the input and output variables are first normalized linearly in the range of 0 and 1 , the normalization is done using the following equation:

$\bar{X}=\frac{X-X_{\min }}{X_{\max }-X_{\min }}$

where $\bar{X}$ is the standardized value of the input, $\mathrm{X}$ is the original data set, $X_{\min }$ and $X_{\max }$ are respectively, the minimum and maximum of the actual values, in all observations. The main reason for standardizing the data matrix is that the variables are usually measured in different units. By standardizing the variables and recasting them in dimensionless units, the arbitrary impact of similarity between objects is removed.

\section{Data}

The results show discharge output of models in calibration and validation periods based on observed data. The training input dataset includes total 2557 data records between 1998 and 2004. The testing input dataset consists of a total 729 data record, observed in the last 2 years (2005-2007).

\section{Evaluation criteria}

Table 3 shows evaluation criteria that use in this study. The root-mean square error (RMSE) evaluates how closely predictions match observations. Values may range from 0 (perfect fit) to $+\infty$ (no fit) based on the relative range of the data. The coefficient of determination, $R$, known as the square of the sample correlation coefficient, ranges from 0 to 1 and describes the amount of observed variance explained by the model. A value of 0 implies no correlation, while a value of 1 suggests that the model can explain all of the observed variance. The Nash-Sutcliffe coefficient 
Table 3 List of elevation criteria

\begin{tabular}{|c|c|c|c|}
\hline No. & Validation statistics & Expression & Range \\
\hline 1 & ENS & $1-\frac{\sum_{i=1}^{n}\left(O_{i}-S_{i}\right)^{2}}{\sum_{i=1}^{n}\left(O_{i}-\bar{O}\right)^{2}}$ & $-\infty<\mathrm{E}_{\mathrm{NS}} \leq 1$ Perfect $: 1$ \\
\hline 2 & $\mathrm{R}$ & $\frac{\sum_{i=1}^{n}\left(O_{i}-\bar{O}\right) \cdot\left(S_{i}-\bar{S}\right)}{\sqrt{\sum_{i=1}^{n}\left(O_{i}-\bar{O}\right)^{2} \cdot \sum_{i=1}^{n}\left(S_{i}-\bar{S}\right)^{2}}}$ & $0 \leq \mathrm{R} \leq 1$ Perfect $: 1$ \\
\hline 3 & RMSE & $\sqrt{\frac{1}{n} \cdot \sum_{i=1}^{n}\left(O_{i}-S_{i}\right)^{2}}$ & $0 \leq \mathrm{RMSE}<\infty$ Perfect $: 0$ \\
\hline 4 & PWRMSE & $\sqrt{\frac{1}{n} \cdot \sum_{i=1}^{n}\left(O_{i}-S_{i}\right)^{2} \cdot\left(\frac{O_{i}+\bar{O}}{2 O}\right)}$ & $0 \leq P W R M S E<\infty$ Perfect $: 0$ \\
\hline 5 & ME & $\frac{1}{n} \cdot \sum_{i=1}^{n}\left(O_{i}-S_{i}\right)$ & $-\infty<\mathrm{ME}<\infty$ Perfect: 0 \\
\hline
\end{tabular}

$\mathrm{O}_{\mathrm{i}}$ obsrved, $\mathrm{S}_{\mathrm{i}}$ simulated, $\mathrm{n}$ number of data, $\overline{\mathrm{O}}$ mean observed, $\overline{\mathrm{S}}$ mean simulated of Efficiency, ENS, measures the model's ability to predict variables different from the mean and gives the proportion of the initial variance accounted for by the model (Nash and Sutcliffe 1970). PWRMSE is implicitly a measure of the comparison of the magnitudes of the peaks, volumes, and times of peak of the simulated and measured hydrographs.

\section{Results and discussion}

\section{Daily streamflow simulation Sy HSPF model}

The daily discharge data from 1998 to 2004 and from 2005 to 2007 were utilized for 'calibration and training' and 'validation and testing' the model approach, respectively. Table 4 shows the values of calibrated parameters in this study. For example, LZSN in Table 4 is an average value $38.1 \mathrm{~mm} / \mathrm{h}$ that has been estimated according to the Linsley equation (Linsley et al. 1988). Linsley equation for the LZSN estimation is LZSN $=100+0.25 \times$ (Yearly mean precipitation). For estimation of the other parameters, BASINS Technical Note 6 (EPA 2001) has been utilized. Figures 5 and 6 show the observed and simulated hydrographs for calibration and validation periods, respectively. These figures present good agreement between observed and simulated daily runoff in the calibration and validation periods. The correlation coefficients for calibration and validation periods are 0.814 and 0.806 , respectively. It implies that HSPF simulation is acceptable. Moreover, Nash-Sutcliff coefficient (model efficiency) is 0.87 in
Table 4 Values of parameters, used in simulation in HSPF model

calibration period and 0.76 in validation period. NashSutcliffe efficiency coefficient value less than 0.5 are considered as unacceptable, while values greater than 0.6 are considered as good and greater than 0.8 are considered excellent results. Therefore, HSPF has been presented good daily runoff simulation. Results show that HSPF simulation of watershed discharge is acceptable in calibration period and can be used in this research.

\section{Daily streamflow simulation by ANN model}

The most common ANN network is the feed-forward network, which uses the back-propagation algorithm for training (Bougadis et al. 2005). The numbers of neurons contained in the input and output layers are determined by the number of input and output variables of a given system. The size or number of neurons of a hidden layer is an important consideration when solving problems using 


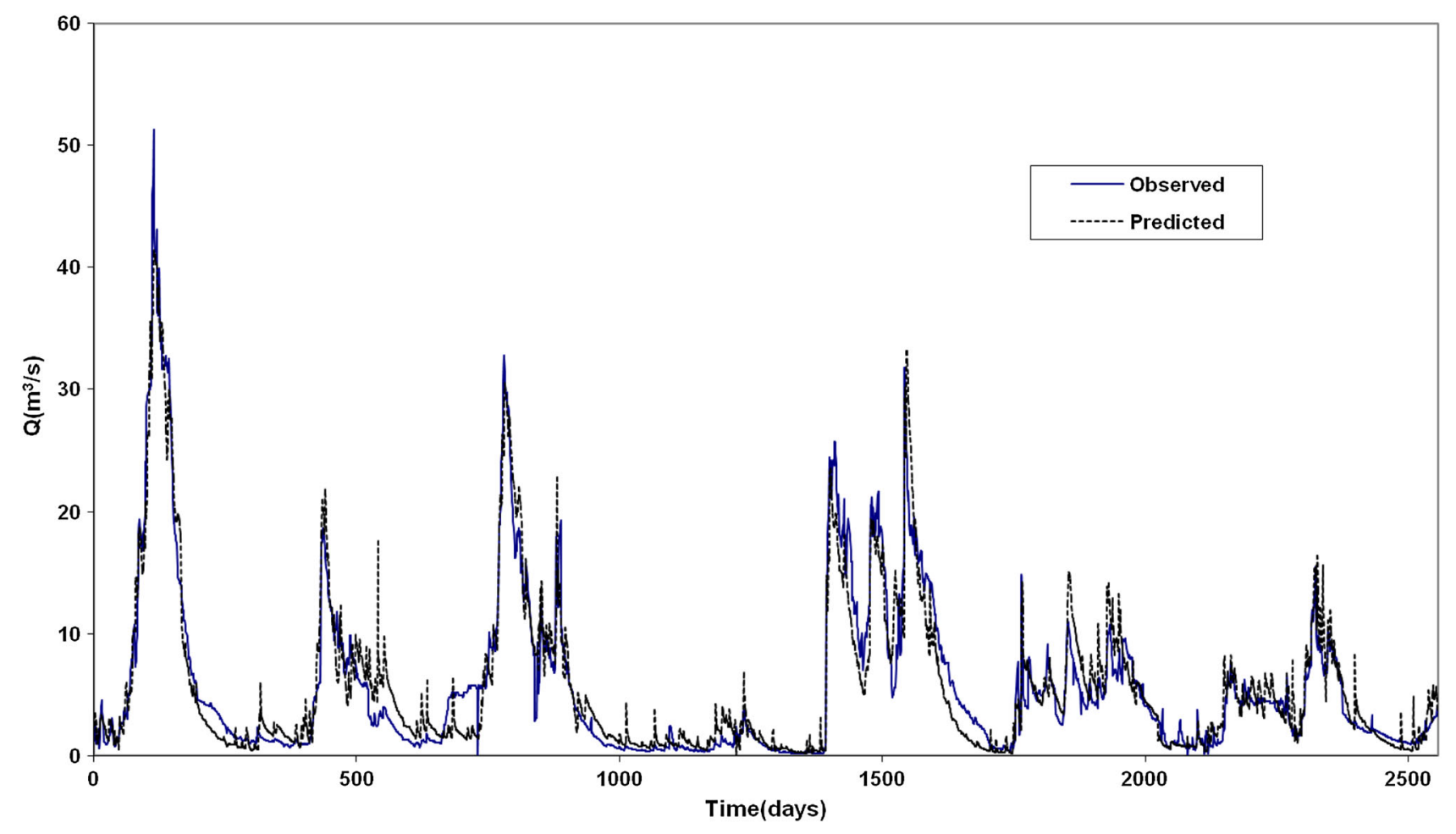

Fig. 5 Simulated and observed hydrographs for calibration period for HSPF model

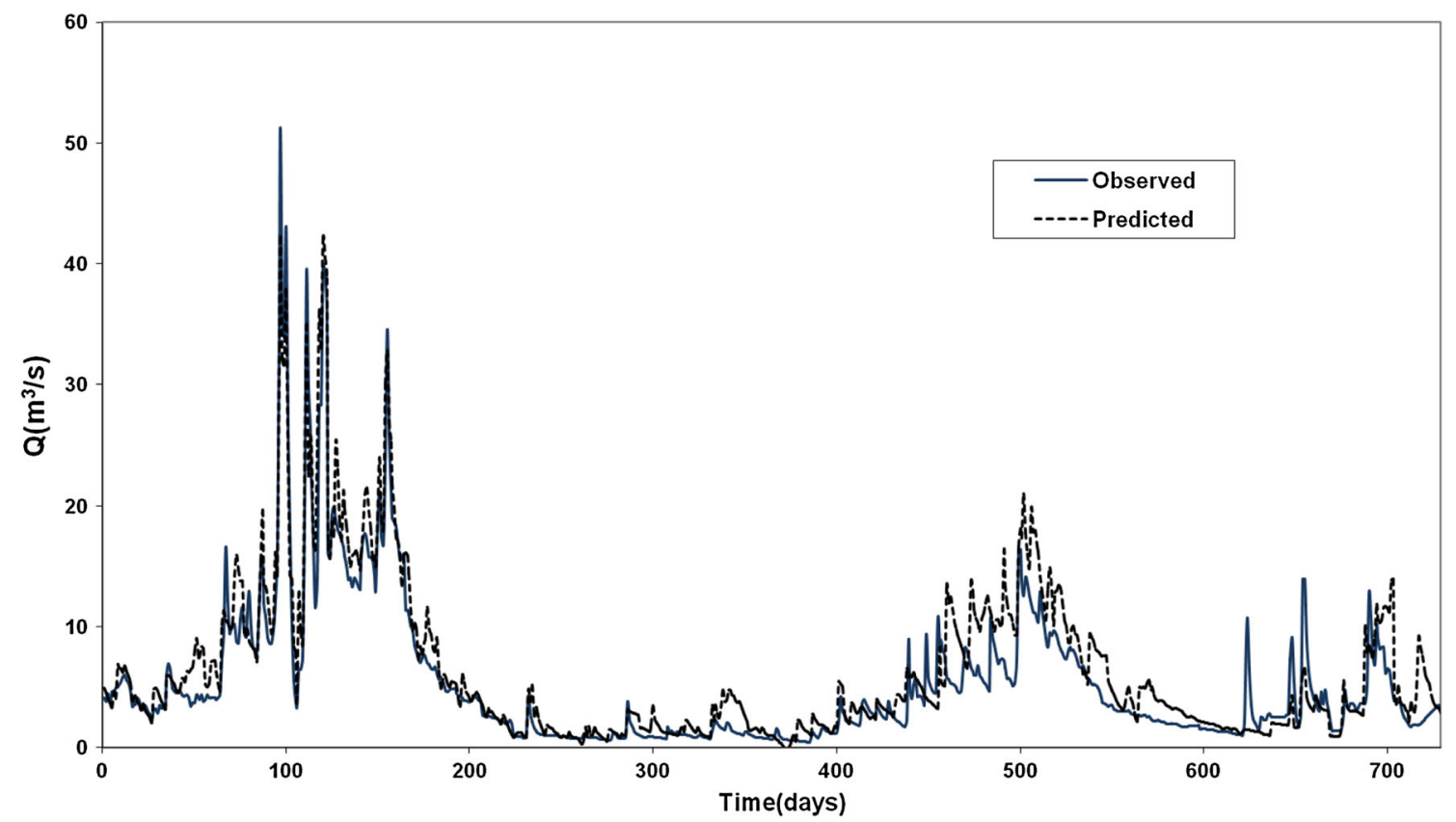

Fig. 6 Simulated and observed hydrographs for validation period for HSPF model

multilayer feed-forward networks. If there are fewer neurons within a hidden layer, there may not be enough opportunity for the neural network to capture the intricate relationships between indicator parameters and the computed output parameters. Here, we use the three-layer FFNN with one hidden layer and the common trial and error method to select the number of hidden nodes. Too many hidden layer neurons not only require a large 


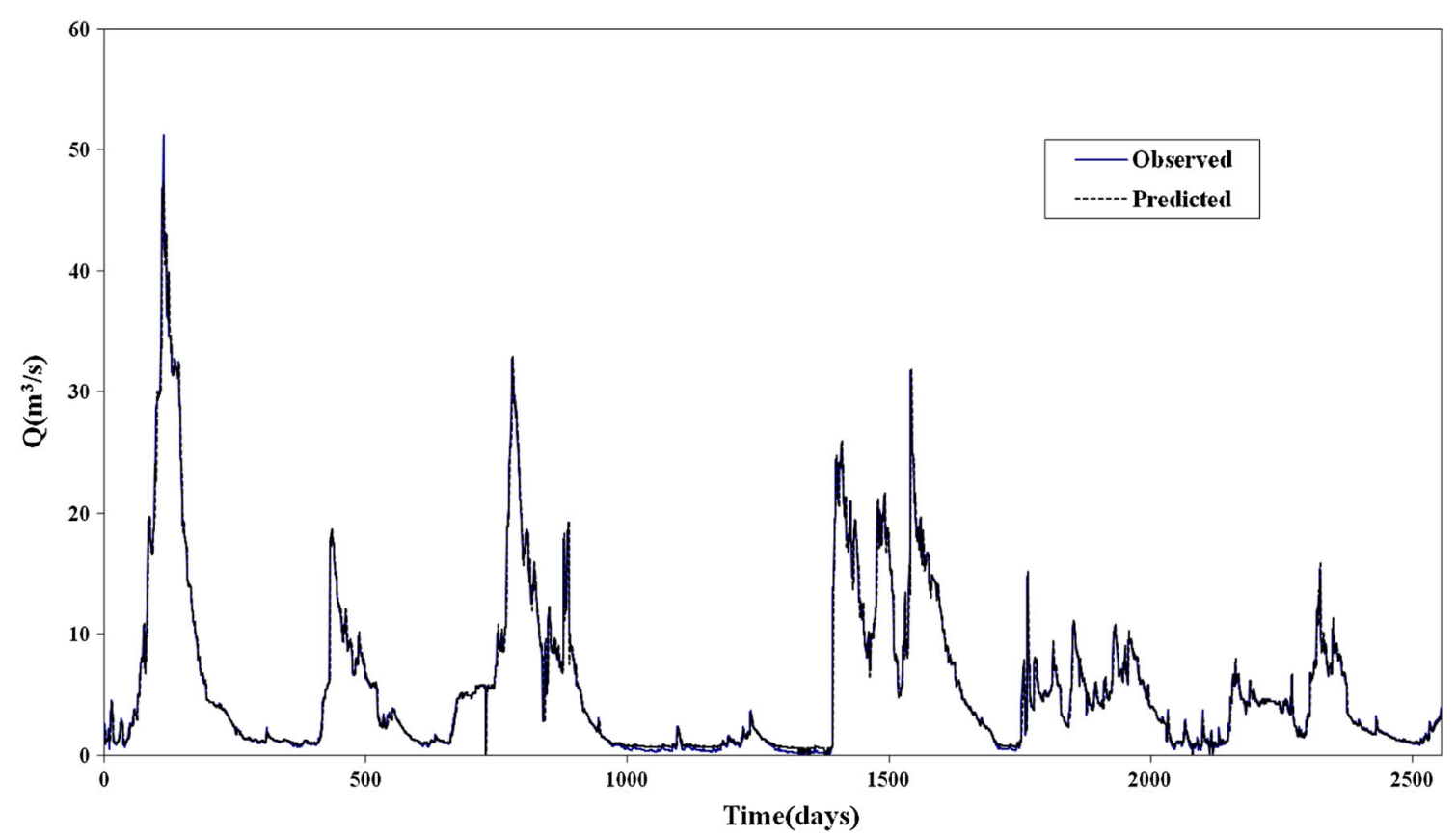

Fig. 7 Analysis plot for daily flow in calibration period with ANN model $\left(\mathrm{m}^{3} / \mathrm{s}\right)$

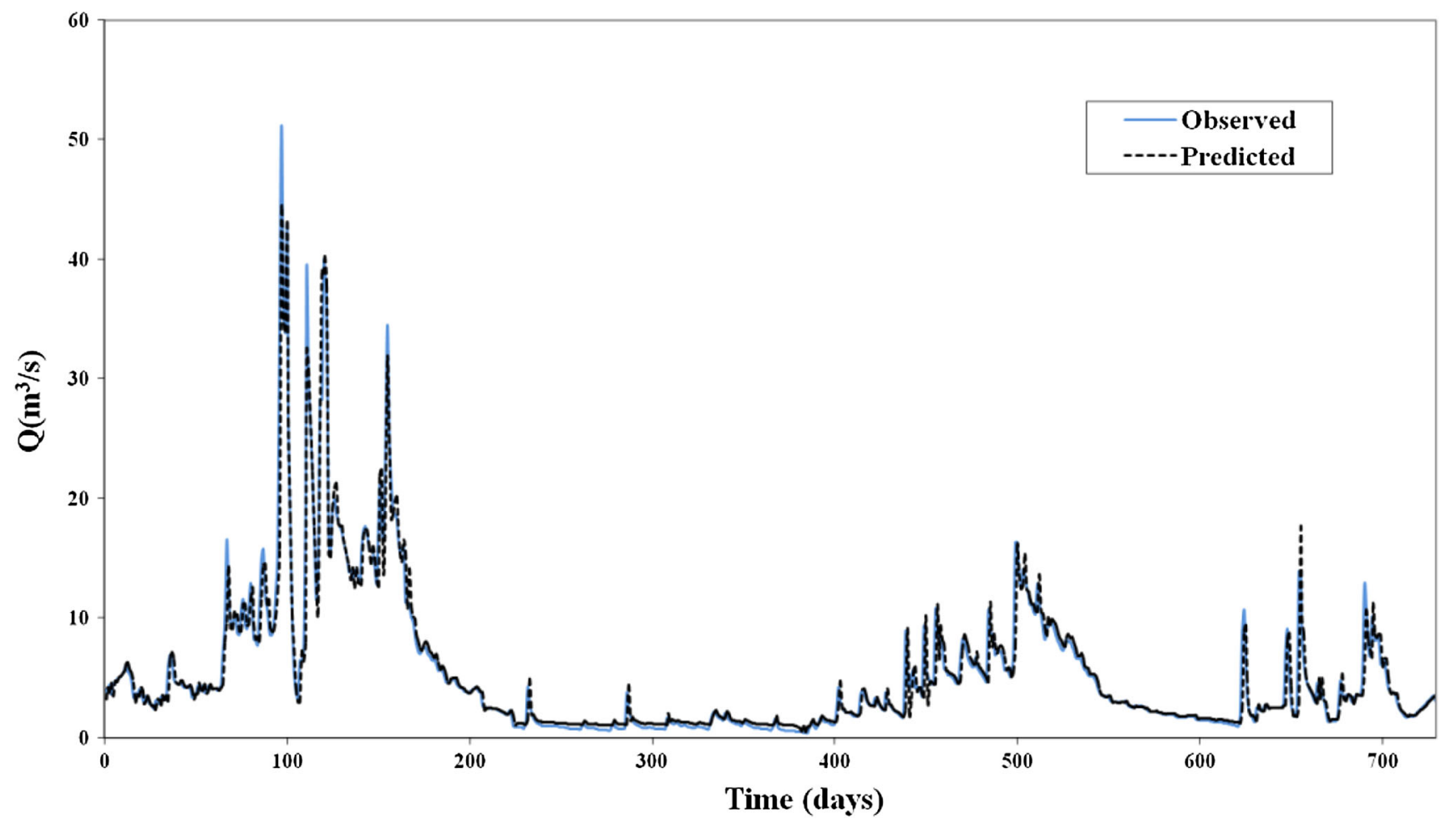

Fig. 8 Analysis plot for daily flow in validation period with ANN model $\left(\mathrm{m}^{3} / \mathrm{s}\right)$

computational time for accurate training, but may also result in overtraining. A neural network is said to be "overtrained" when the network focuses on the characteristics of individual data points rather than just capturing the general patterns present in the entire training set.
Figures 7 and 8 show discharge output of ANN model in calibration and validation periods based on observed data, respectively. A very good match is obtained between the observed runoff values and those computed by the ANN model for the training data in all the input. The 
Table 5 Performances of HSPF and FFNN model

\begin{tabular}{lllllllllll}
\hline \multicolumn{1}{c}{ Calibration set } & \multicolumn{3}{c}{ Validation set } \\
\hline Evaluation criteria & Name model & 1998 & 1999 & 2000 & 2001 & 2002 & 2003 & 2004 & 2005 & 2006 \\
$\mathrm{E}_{\mathrm{Ns}}$ & ANN & 0.982 & 0.910 & 0.949 & 0.953 & 0.919 & 0.836 & 0.873 & 0.921 & 0.694 \\
& HSPF & 0.963 & 0.582 & 0.930 & 0.926 & 0.803 & 0.565 & 0.728 & 0.933 & 0.526 \\
$R^{2}$ & ANN & 0.992 & 0.961 & 0.976 & 0.983 & 0.962 & 0.950 & 0.955 & 0.963 & 0.961 \\
& HSPF & 0.982 & 0.821 & 0.967 & 0.980 & 0.919 & 0.892 & 0.915 & 0.973 & 0.790 \\
ME & ANN & 0.281 & 0.306 & 0.148 & -0.457 & 0.551 & 0.419 & 0.348 & 0.211 & 0.262 \\
& HSPF & 0.414 & -0.487 & -0.498 & 0.247 & 0.721 & -0.738 & -0.451 & -0.927 & -1.153 \\
RMSE & ANN & 1.149 & 1.146 & 1.684 & 1.469 & 1.817 & 1.093 & 0.953 & 2.289 & 1.724 \\
& HSPF & 2.189 & 2.472 & 1.977 & 1.849 & 2.840 & 1.779 & 1.399 & 2.097 & 2.861 \\
PWRMSE & ANN & 2.148 & 1.536 & 2.049 & 2.068 & 2.224 & 1.229 & 1.188 & 3.392 & 2.263 \\
& HSPF & 3.02 & 2.608 & 2.375 & 2.975 & 3.196 & 1.981 & 1.519 & 2.710 & 3.279 \\
\hline
\end{tabular}

Fig. 9 Scatter plot for daily flow in calibration period with HSPF model $\left(\mathrm{m}^{3} / \mathrm{s}\right)$

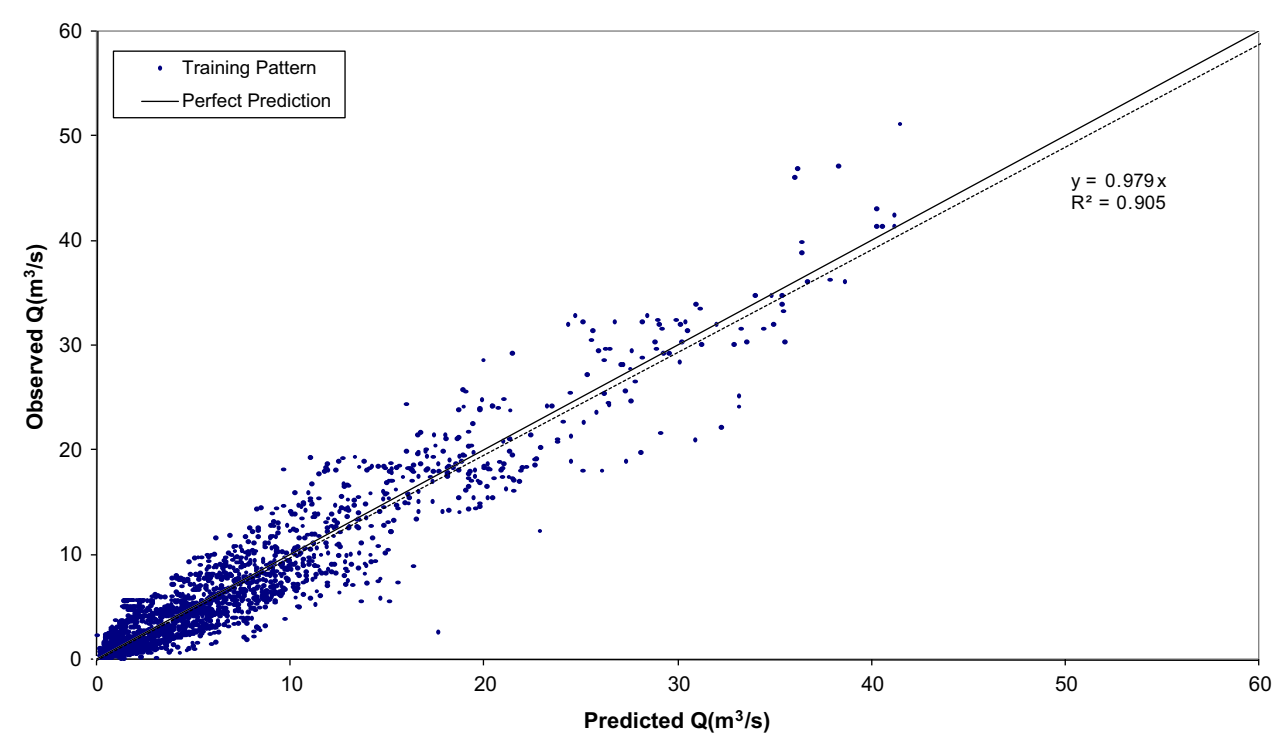

performance of ANN model during high flows, both during summer, autumn and winter are perfect and better than that of the HSPF model, but in low flows, a little bit above estimation is observed. This indicates the robustness of the ANN model and confirms its capability for runoff simulation within acceptable accuracy. The testing input dataset consists of a total 729 data record, observed in the last 2 years (2005-2007). The $R^{2}$ for the ANN model 0.950 for the calibration period and 0.962 for the validation period.

\section{Comparison of HSPF and ANN models}

During comparison of results, the words such as 'calibration' and 'validation' of HSPF model were used as similar to training and testing of ANN model, respectively. To estimate the relative performance of the models in runoff simulation, values of evaluation criteria obtained from both ANN and HSPF models were compared. The evaluation criteria of ANN model obtained during training were compared with the corresponding evaluation criteria obtained during HSPF calibration. The values of Ens, $R^{2}$, ME, RMSE and PWRMSE are Statistical evaluation criteria that have been showed in Table 5. Similarly, the testing results of the ANN model were compared with the validation results of HSPF model.

The ENs for the HSPF model ranged from 0.565 to 0.963 for the calibration period and from 0.526 to 0.933 for the validation period. Similarly, The $R^{2}$ for the HSPF model ranged from 0.821 to 0.98 for the calibration period and from 0.793 to 0.97 for the validation period. The ME ranged from -0.738 to 0.721 for the calibration period and from -1.153 to -0.927 for the validation period. Also, The RMSE ranged from 1.399 to 2.84 for the calibration period and from 2.097 to 2.681 for the validation period. The PWRMSE for HSPF model ranged from 1.519 to 3.196 for the calibration period and from 2.71 to 3.279 for the validation period.

The ENs for the ANN model ranged from 0.836 to 0.982 for the calibration period and from 0.694 to 0.921 for the 
Fig. 10 Scatter plot for daily flow in validation period with HSPF model $\left(\mathrm{m}^{3} / \mathrm{s}\right)$

Fig. 11 Scatter plot for daily flow in calibration period with ANN model $\left(\mathrm{m}^{3} / \mathrm{s}\right)$
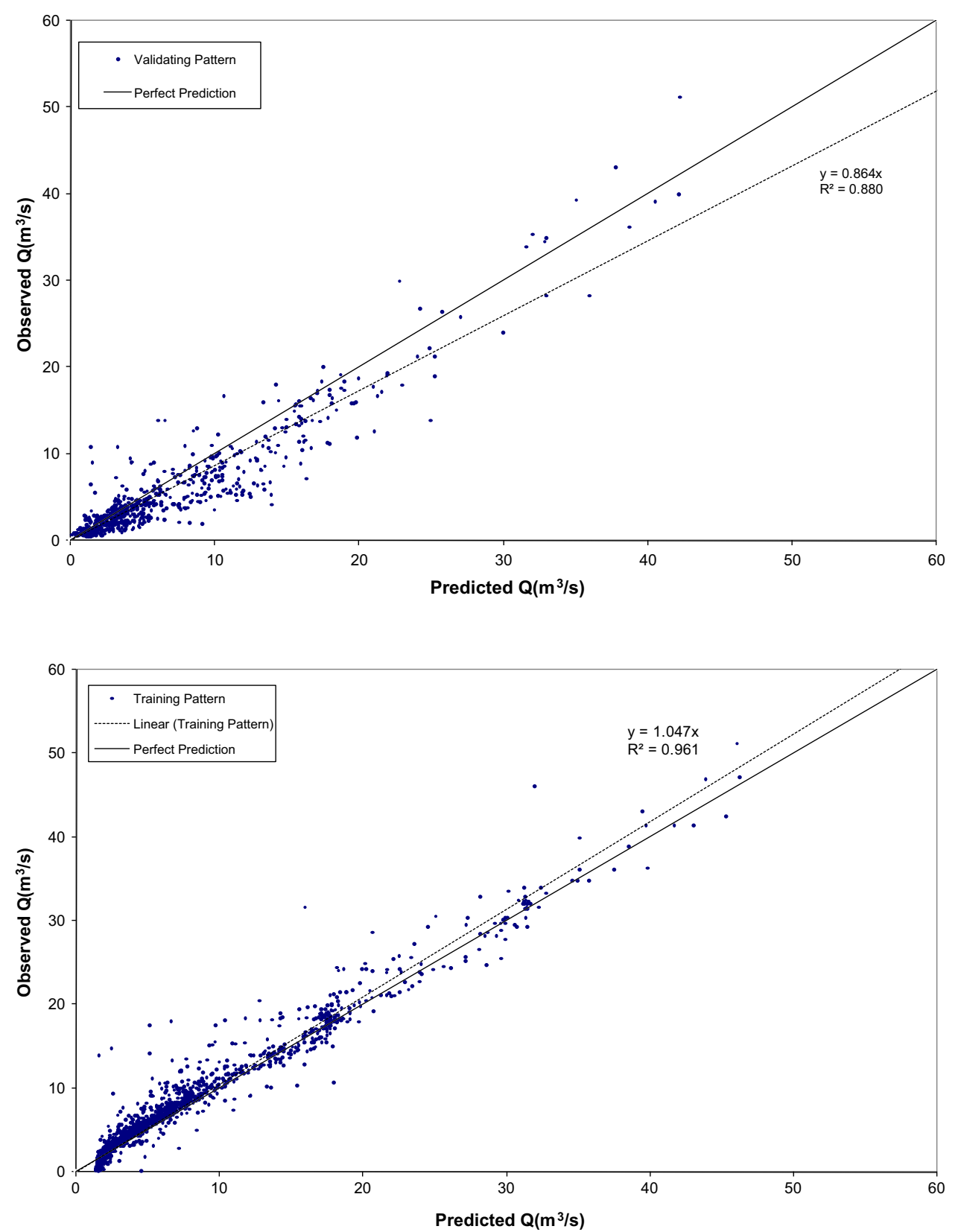

validation period. Similarly, The $R^{2}$ for the ANN model ranged from 0.950 to 0.992 for the calibration period and from 0.961 to 0.963 for the validation period. The ME ranged from -0.457 to 0.551 for the calibration period and from 0.211 to 0.262 for the validation period. Also, The RMSE ranged from 0.953 to 1.817 for the calibration period and from 1.724 to 2.289 for the validation period. The PWRMSE for ANN model ranged from 1.536 to 2.224 for the calibration period and from 3.392 to 2.263 for the validation period.

The results indicated that both models were generally able to simulate stream flow well during both the calibration/validation periods. However, the simulated stream flows by ANN were better than those predicted by HSPF during the calibration and validation periods. The runoff simulation of the ANN model was found to be better than the HSPF model during calibration and validation as revealed from the values of the evaluation criteria. There was a considerable difference between the values of ENs obtained from the ANN and HSPF models for the year 2004 (Table 5). Similar results were obtained during model validation period as well. In this study of the HSPF model, the values of Nash-Sutcliffe coefficients were found to be lower than that of the ANN model. This confirms that ANN model is well capable of describing the non-linear relationship between the input and output. 
Fig. 12 Scatter plot for daily flow in validation period with ANN model $\left(\mathrm{m}^{3} / \mathrm{s}\right)$

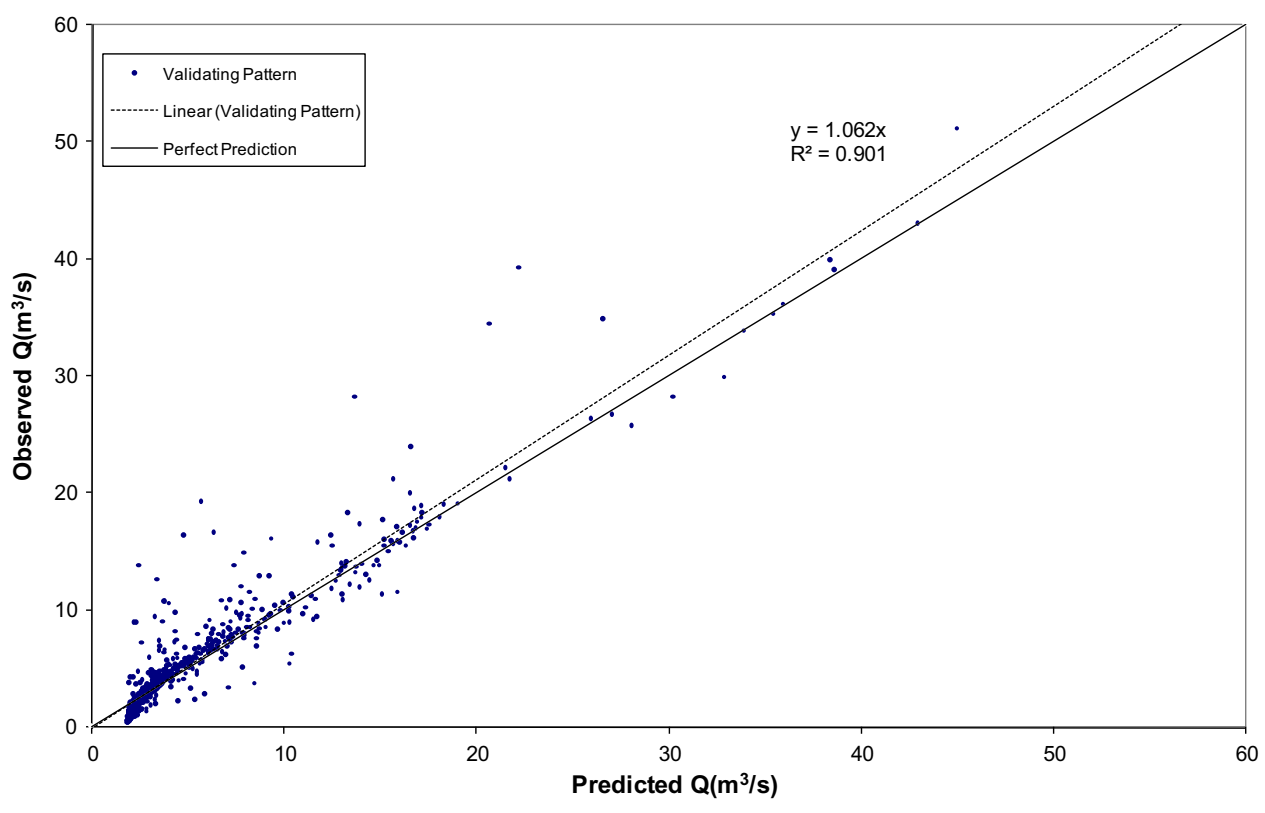

Figures 9 and 10 show the scatter plots of observed and computed runoff values for the calibration and validation periods for the HSPF model. The scatter plot is well spread over the ideal line for this the watershed (Fig. 9). In the validation period, the plot is shifted towards one side. The shift from the ideal line shows the possibility of systematic errors. Similar scatter plots for the ANN model, shown in Figs. 11 and 12, exhibit a closer scatter to the ideal line, thus indicating good runoff simulation for the Gharehsoo River watershed. The scatter for the ANN model is obviously better than that of the HSPF model. These scatter plots are considered to have been accounted for by the application of the ANN model as is revealed by relatively more symmetrical scatter in figures. The ANN model was found to be more successful than the HSPF in relation to better forecast of peak flow. The results of this study, in general, showed that ANNs can be powerful tools in runoff simulation.

\section{Conclusion}

This paper reports the results of a comparison of two different models for runoff simulation in the Gharehsoo River watershed, Iran, in the period 1998-2007. The performance of models in 'calibration and training' and 'validation and testing' stages are compared with the observed runoff values to identify the best fit forecasting model based upon a number of selected performance criteria. The comparison results show that the ANN model have better performances in forecasting of runoff from HSPF. By considering a good training process and suitable algorithms and nodes, the prediction is more accurate. Once the architecture of the network is defined, weights are calculated so as to represent the desired output through a learning process where the ANN is trained to obtain the expected results. The neural network could predict runoff accurately, with good agreement between the observed and predicted values compared to the HSPF model. The ANNs are capable for daily simulation of runoff. However, in low flows, a little bit above estimation is observed. As in hydrologic models, ANN does not require watershed information and other physical parameters in the modeling process, which reduces the complexities of modeling the system. Required time for the calibration of the ANNs is much less as compared to the HSPF. Also, for calibration ANN model is need less expertise and experiences. In comparison to HSPF model, less data is required for simulation using the ANNs. If a number of scenarios are to be made to investigate the response of the catchment, the HSPF may prove advantageous in comparison to the ANNs. One of advantages of the HSPF model is to make reliable runoff simulation when there are available climate and soil data at ungauged site. The results of this study were in a good agreement with earlier studies conducted for, in general, the HSPF and ANN comparison in daily simulations, specifically runoff prediction performance.

\section{References}

Abdulla F, Eshtawi T, Assaf H (2009) Assessment of the impact of potential climate change on the water balance of a semi-arid watershed. Water Resour Manag 23:2051-2068 
Abrahart RJ, See LM (2007) Neural network emulation of a rainfallrunoff model. Hydrol Earth Syst Sci 4:288-326

Al-Abed NA, Whiteley HR (2002) Calibration of the Hydrological Simulation Program Fortran (HSPF) model using automatic calibration and geographical information systems. Hydrol Process 16:3169-3188

Albek M, Ogutveren U, Albek E (2004) Hydrological modeling of Seydi Suyu watershed (Turkey) with HSPF. J Hydrol 285:260-271

Banaei FK, Zinatizadeh AAL, Mesgar M, Salari Z (2012) Dynamic performance analysis and simulation of a full scale activated sludge system treating an industrial wastewater using artificial neutral network. Int J Eng Trans A: Basics 26(5):465-472

Bicknel BR, Imhoff JC, Kittle JL, Donigian AS, Johanson RC (1993) Hydrological simulation program-fortran user's manual for release 10, Environmental Research Laboratory Office of Research and Development U.S. Environmental Protection Agency: Athens, GA, EPA/600/R-93/174

Bicknell BR, Imhoff JC, Kittle JL, Jobes TH, Donigian AS (2005) Hydrological simulation program fortran: Version 12.2. User's Manual

Bougadis J, Adamowski K, Diduch R (2005) Short-term municipal water demand forecasting. Hydrol Process 19:137-148

Bray M, Han D (2004) Identification of support vector machines for runoff modeling. J Hydroinf 6:265-280

Chang FJ, Chiang YM, Chang LC (2007) Multi-step-ahead neural networks for flood forecasting. Hydrol Sci J 54:114-130

Chua HCL, Wong TSW, Sriramula LK (2008) Comparison between kinematic wave and artificial neural network models in eventbased runoff simulation for an overland plane. J Hydrol $357: 337-348$

Crawford HH, Linsley RK (1996) Digital simulation in hydrology: Stanford watershed model IV. Technical Report No. 39, Dept. of Civil Eng., Stanford University, Stanford, CA

Dawson CW, Wilby RL (2001) Hydrological modeling using artificial neural networks. Prog Phys Geogr 25:80-108

de Vos NJ, Rientjes THM (2005) Constraints of artificial neural networks for rainfall-runoff modeling: trade-offs in hydrological state representation and model evaluation. Hydrol Earth Syst Sci 9:111-126

Donigian AS, Crawford NH (1976) Modelling Nonpoint Pollution from the Land Surface, Environmental Research Laboratory: Athens, Georgia. EPA/600/3-76-083

Donigian AS, Davis HH (1987) User's Manual for Agricultural Runoff Management (ARM) Model, EPA-600/3-78-080, USEPA, Athens, GA, $112 \mathrm{p}$

Donigian AS, Jr Huber WC (1991) Modeling of nonpoint source water quality in urban and non-urban areas, EPA-600/3-91-039, USEPA, Athens, GA, 78 p

Donigian AS, Imhoff JC, Bicknell BR, Kittle JL (1984) Application guide for hydrological simulation program-fortran (HSPF). United States Environmental Protection Agency (EPA)-600/384-065

Donigian AS, Jr Bicknell BR, Imhoff JC (1995) Hydrological simulation program-FORTRAN (HSPF). In: Singh VP (ed) Computer models of watershed hydrology, Water Resources Pubs, Highlands Ranch, CO, pp 395-442

Donigian AS, Jr Chinnaswamy RV, Jobes TH (1997) Conceptual Design of Multipurpose Detention Facilities for Flood Protection and Nonpoint Source Pollution Control, AquaTerra Consultants, Mountain View, CA, $151 \mathrm{p}$

EPA, BASINS Technical Note 6, 2001 Estimating Hydrology and Hydraulic Parameters for HSPF, US
Filho AJP, dos Santos CC (2006) Modeling a densely urbanized watershed with an artificial neural network, weather radar and telemetric data. J Hydrol 317:31-48

Fontaine TA, Jacomino VMF (1997) Sensitivity analysis of simulated contaminated sediment transport. J Am Water Resour Assoc $33: 313-326$

Goel A (2009) ANN based modeling for prediction of evaporation in reservoirs (Research Note). Int $J$ Eng. Trans A: Basics 22(4):351-358

Hagan MT, Menhaj M (1994) Training feedforward networks with the Marquardt algorithm. IEEE Trans Neural Netw 5(6):989-993

Hagan MT, Demuth HB, Beale H, Jesus OD (1996) Neural network design. PWS Publishing, Boston, MA

Inc Hydrocomp (1977) Hydrocomp water quality operations manual. Hydrocomp Inc, Palo Alto

Javan K, Lialestani MRFH, Moosavian N (2015) Assessment of the impacts of nonstationarity on watershed runoff using artificial neural networks: a case study in Ardebil, Iran. J Model Earth Syst Environ 1:1-10

Kahya E, Dracup JA (1993) US stream flow patterns in relation to the El Nino/southern oscillation. Water Resour Res 28:491-503

Kingston GB, Maier HR, Lambert MF (2005) Calibration and validation of neural networks to ensure physically plausible hydrological modeling. J Hydrol 314:159-176

Kumar ARS, Sudheer KP, Jain SK, Agarwal PK (2005) Rainfallrunoff modeling using artificial neural networks: comparison of network types. Hydrol Process 19:1277-1291

Linsley RK, Kohler MA, Paulhus JLH (1988) Hydrology for engineers. McGraw-Hill, New York

Mark SJ, William FC, Vishal KM, Tammo SS, Erin SB, Jan B (2003) Application of two hydrologic models with different runoff mechanisms to a hillslope dominated watershed in the northeastern US: a comparison of HSPF and SMR. J Hydrol 284:57-76

Morid S, Gosain AK, Keshari AK (2002) Comparison of the SWAT model and ANN for daily simulation of runoff in snowbound ungauged catchments. In: Fifth international conference on hydroinformatics, Cardiff, UK

Mutlu E, Chaubey I, Hexmoor H, Bajwa SG (2008) Comparison of artificial neural network models for hydrologic predictions at multiple gauging stations in an agricultural watershed. Hydrol Process 22:5097-5106

Nash JE, Sutcliffe JV (1970) River flow forecasting through conceptual models part I-a discussion of principles. J Hydrol 10(3):282-290

Nayak PC, Sudheer KP, Jain SK (2007) Rainfall-runoff modeling through hybrid intelligent system. Water Res 43:1-17

See L, Openshaw S (2000) Applying soft computing approaches to river level forecasting. Hydrol Sci J 44(5):763-779

Shamseldin AY (1997) Application of a neural network technique to rainfall-runoff modeling. J Hydrol 199:272-294

Srinivasan MS, Hamlett JM, Day RL, Sams JI, Peterson GW (1998) Hydrologic modeling of two glaciated watersheds in northeast Pennsylvania. J Am Water Resour Assoc 34:963-978

Srivastava P, McNair JN, Johnson TE (2006) Comparison of processbased and artificial neural network approaches for streamflow modelling in an agricultural watershed. J Am Water Resour Assoc 42:545-563

Tokar AS, Johnson PA (1999) Rainfall-runoff modeling using artificial neural networks. J Hydrol Eng 4:232-239

Tokar AS, Markus M (2000) Precipitation-runoff modelling using artificial neural networks and conceptual models. J Hydrol Eng 4:232-239 
Xiong LH, Shamseldin AY, O'Connor KM (2001) A nonlinear combination of the forecasts of rainfall-runoff models by the first order Takagi-Sugeno fuzzy system. J Hydrol 245:196-217 Zadeh LA (1965) Fuzzy sets. Inf Control 8:338-353

Zarriello PJ, Ries KG (2000) A Precipitation-Runoff Model for Analysis of the Effects of Water Withdrawals on Streamflow,
Ipswich River Basin, Massachusetts, USGS Water- Resources Investigations Report 00-4029, $99 \mathrm{p}$

Zhang B, Govindaraju RS (2000) Prediction of watershed runoff using Bayesian concepts and modular neural networks. Water Resour Res 36:753-762 